\title{
X-linked intellectual disability-cerebellar hypoplasia syndrome
}

INSERM

\section{Source}

INSERM. (1999). Orphanet: an online rare disease and orphan drug data base. $\underline{X \text {-linked }}$ intellectual disability-cerebellar hypoplasia syndrome. ORPHA:137831

X-linked intellectual deficit-cerebellar hypoplasia, also known as OPHN1 syndrome, is a rare syndromic form of cerebellar dysgenesis characterized by moderate to severe intellectual deficit and cerebellar abnormalities. 